\title{
Impact of Electromagnetic Stirring on the Gas Metal Arc Welding of an MAR-M247 Superalloy
}

\section{Yu-Chih Tzeng}

National Defense University

Cheng-Yu Lu

Nation Kaohsiung University of Science and Technology

RenYu Chen ( $\nabla$ renyu.tw@gmail.com )

National Cheng Kung University

\section{Research Article}

Keywords: electromagnetic stirring, gas tungsten arc welding, MAR-M247, superalloy

Posted Date: September 21st, 2021

DOI: https://doi.org/10.21203/rs.3.rs-902021/v1

License: (1) This work is licensed under a Creative Commons Attribution 4.0 International License. Read Full License 


\section{Abstract}

In this paper, the impact of electromagnetic stirring (EMS) on the gas metal arc welding (GATW) of an MAR-M247 superalloy was investigated. Results revealed that, without electromagnetic stirring, it was easy for carbides in the heat-affected zone (HAZ) of the weld bead to liquefy during welding, leading to weld bead cracks. Electromagnetic stirring refined the grains in the HAZ and the weld bead, leading to grain strengthening and subsequently resulting in the effective improvement in the hardness of the weld bead. In addition, electromagnetic stirring significantly facilitated the formation of the weld bead by the removal of large inclusions which in turn effectively improved crack resistance at the joint. It also accelerated the floating up of gas holes thereby reducing the generation of gas hole defects.

\section{Introduction}

MAR-M247 is a typical cast polycrystalline nickel-based superalloy, which was developed by Martin Marietta in the late 1970s [1]. It exhibits excellent castability at high temperatures, as well as satisfactory creep resistance and hot corrosion resistance [2-9]; it is the main material used for the fabrication of gas turbine blades in the aviation and energy industries $[8,10]$. The MAR-M247 superalloy exhibits an extremely complex composition, comprised of several solid-solution strengthening elements and precipitation-hardening elements [7, 11-13]. Its microstructure mainly comprises austenite $\gamma$-phase base, $Y^{\prime}$ strengthening phase, $\gamma-\gamma$ ' eutectic structure [14-17], and various borides and carbides crystallized by solidification [14]. The Ni base exhibits limited solubility to these trace elements. The trace elements interact with $\mathrm{Ni}$ in the base during welding, to form a low-melting-point eutectic phase, and segregate at the grain boundaries, leading to the precipitation of brittle carbides [18-20] during welding, resulting in clear hot cracks on the weld bead. This is also one of the main reasons that MAR-M247 is not applicable for repair welding.

Generally, the Ni-base superalloys (e.g., Hastelloy $\mathrm{x}$ ) can be welded by fusion welding, such as Gas tungsten arc welding (GTAW), gas metal arc welding (GMAW), shield metal arc welding (SMAW), and submerged arc welding (SAW)[10]. However, owing to the poor thermal conductivity, strong viscosity of the liquid metal, and low oxidation resistance of the alloy elements [18], the molten pool of the MARM247 superalloy cannot be wetted and developed as easily as the molten pool of steel. Therefore, the formation of the weld bead is poor, its penetration is shallow, and fluidity cannot be improved even with an increase in the current, although the hot crack sensitivity of the weld bead can be increased by an increase in the current. GTAW is typically used for the welding of Ni-based superalloys [22] exhibiting a clean surface after welding. However, if the welding heat input is high during the implementation of multipass welding, the eutectic structure of the low-melting-point weld head at the grain boundaries of the HAZ is prone to liquefaction under welding stress, leading to defects in the HAZ, which can include liquefaction defects, weld bead defects, humped weld bead defects, weld erosion, and gas holes. Therefore, it is crucial to employ a modified welding method to solve this processing problem. 
Laser welding [23], electron-beam welding [24], friction stir welding [25, 26], and other advanced welding methods generate less welding stress, thereby helping to reduce welding hot cracks; however, these welding methods are not yet practically applicable in repair welding. Recently, electromagnetic welding (EMS) has come to be recognized as an effective method for facilitating bead formation, as well as enhancing the microstructure and mechanical properties of the weld [27-33]. EMS can effectively decrease welding defects, such as weld erosion, hump beads, gas holes, and cracks during fusion welding. In 1971, Tseng and Savage [34] reported that electromagnetic stirring can improve the shape coefficient of the GTAW weld bead and reduce its sensitivity to hot cracking, consequently improving crack resistance. Under the application of an external magnetic field, the proportion of coarse grains in the weld bead decreased, and fine equiaxed grains were formed. The average grain size decreased, thereby enlarging the grain boundary area and enhancing the strengthening effect of the grain boundaries. Consequently, joint strength was improved. The addition of a magnetic field could facilitate optimization of the distribution of inclusions in the weld bead. Inclusions are dispersed in the metal of the weld bead as second-phase particles, which serve as the base for the nucleation of weld bead grains. Magnetic stirring on the other hand can alleviate the segregation of alloying elements in the molten pool, thereby considerably reducing the tendency of hot cracking. In addition, it can change the mass transfer and heat transfer processes of the molten pool [27] and the orientation of grain growth. Large angle grain orientations can increase the energy required for the development of hot cracks, thereby effectively hindering their expansion. Currently, ESM magnetic field control technology has been developed for metal welding, including stainless steel [35-39], al uminum alloys [32, 40-43], and magnesium alloys [44-47], but it has not been employed for welding of the MAR-M247 superalloy. Therefore, in this study, the effects of GTAW with an EMS device on the mechanical properties and microstructure of the MAR-M247 superalloy are explored.

\section{Experiments}

Table 1 summarizes the composition of the MAR-M247 superalloy used in this experiment, and Fig. 1 shows the equipment comprising the GTAW device along with the EMS device. The EMS metal is fixed on a welding gun, and EMS is powered by the magnetic-field power-supply equipment, which can adjust the magnitude of the current and the frequency of the external magnetic field. The GTAW welder is an automatic welding machine, which utilizes an automatic wire feeding device and can automatically digitalize and adjust the wire feeding speed, movement speed, arc height, current, and voltage, to stabilize the welding parameters for the welding process.

Table 1

Chemical composition of the Mar-M247 superalloy

\begin{tabular}{|lllllllllllll|}
\hline Alloy & C & Cr & Co & W & Mo & Ta & Al & Ti & Hf & Zr & B & Ni \\
\hline Mar-M247 & 0.15 & 8.4 & 11.0 & 10.0 & 0.7 & 3.0 & 5.5 & 1.0 & 1.5 & 0.05 & 0.015 & Bal. \\
\hline
\end{tabular}


The welding methods (Fig. 2) selected herein are (1) bead-on-plate (BOP) and (2) V-shaped butt welding. In the BOP welding test, the alloy specimen is wire cut into $100 \mathrm{~mm} \times 60 \mathrm{~mm} \times 6 \mathrm{~mm}$ plates (Fig. 2 (a)), and welding is executed both with and without a Turbaloy@625 solder for analysis of the differences. Three-pass overlay welding is carried out using the Turbaloy@625 solder and another plate. In the v-butt welding test, the MAR-M247 superalloy ingot is cut into V-shaped joints. The joints are grooved by wire cutting, with a side angle of $45^{\circ}$ and a plate spacing of $5 \mathrm{~mm}$ (Fig. 2 (b)). Before welding, the joints are ground down with sandpaper to remove any oxide film from the surface and in the groove. After grinding, the joints are cleaned with acetone, and v-butt GTAW and GTAW + EMS are conducted. Before v-butt welding, the v-butt plate was subjected to a vacuum solution treatment at $1185^{\circ} \mathrm{C}$ for $2 \mathrm{~h}$, followed by cooling to room temperature in an argon gas atmosphere, to eliminate residual stress from the specimen. After welding, the v-butt welding specimens were subjected to a vacuum solid solution treatment at $1185^{\circ} \mathrm{C}$ for $2 \mathrm{~h}$, followed by cooling to room temperature with argon. Subsequently, after $20 \mathrm{~h}$ of artificial aging in a vacuum at $871^{\circ} \mathrm{C}$ the material is allowed to cool to room temperature in the furnace.

The heat input temperatures of GATW and GATW + EMS during welding are measured using an infrared thermometer. The alloy microstructure is observed using an optical microscope (Olympus BX60M). The metallographic specimens are treated by coarse grinding, fine grinding, and polishing. After polishing, the microstructure of the alloy is observed under different magnifications. Scanning electron microscopy (SEM, JEOL JAM-35Cf, acceleration voltage set at $15 \mathrm{kV}$ ) is employed to observe the morphology of the weld bead and fracture surface. The observations are utilized to understand the microstructure and fracture mechanism of the weld bead. Energy-dispersive spectrometry (EDS) is employed for semiquantitative analysis of intermetallic compounds of the alloy and X-ray analysis is employed for the detection and location of welding defects. Wire cutting and slow cutting machines are used to sample the defects. After sampling, metallographic defects are observed and analyzed by SEM, and EDS and X-ray analysis are employed to analyze the composition surrounding the defects to understand their causes.

The Vicker's hardness test is employed to measure the hardness (load of $500 \mathrm{gf}$ and a loading time of 10 s) and analyze changes in the mechanical properties of the materials after welding. The 10-ton MTS universal testing machine is utilized for tensile testing, which is conducted in the stroke control mode. Throughout the entire process, the tensile test speed rate is divided into two sections: initially, it is 0.2 $\mathrm{mm} / \mathrm{min}$, and when the strain is equal to $1 \%$, it is switched to $2 \mathrm{~mm} / \mathrm{min}$.

\section{Conclusions And Discussion}

\subsection{Microstructural analysis}

Figure 3 shows the microstructure of the as-cast and solution-quenched state of the MAR-M247 nickelbased superalloy. From the as-cast state (Fig. 3 (a)), the microstructure of MAR-M247 is mainly composed of the austenite $y$ phase and a number of Chinese script shaped carbides. However, we find no significant difference between the as-cast state and solution-quenched state (Fig. 3 (b)), indicating that 
the solution-quenched heat treatment does not produce significant changes in the morphology of Chinese script shaped carbides and that the carbides can reach up to $50 \mu \mathrm{m}$ to $100 \mu \mathrm{m}$ in size (Fig. 3 (c)).

Figure 4 shows the SEM microstructure of the solution-quenched state MAR-M247 nickel-based superalloy. The microstructure of the solution-quenched state MAR-M247 austenite $y$ phase is clearly observed in the SEM images (as shown in Fig. 4(a)). In addition to the large number of Chinese script shaped carbides, the fine $\gamma^{\prime}$ strengthening phase, rose-shaped $\gamma$ - $\gamma^{\prime}$ eutectic structure, and thick plated $\gamma^{\prime}$ phase also are found (as shown in Fig. 4(b), 4(c) and 4(d)). Figure 5 shows the results of EPMA analysis of the Chinese script shaped carbides which are mainly composed of $\mathrm{Ti}, \mathrm{Ta}$, and $\mathrm{Hf}$.

\subsection{BOP welding analysis}

Figure 6 shows the arc shapes of GTAW and electromagnetic stirring assisted GTAW. The GATW carried out without an external electromagnetic field exhibits a bell-shaped arc (Fig. 6 (a)), while GATW + EMS exhibits a meteor-shaped arc (Fig. 6 (b)). Figure 7 shows weld bead structure of the solution-quenched state MAR-M247 superalloy welded by bead-on-plane (BOP) welding. There are notably clear waves in the GATW weld bead, while the GATW + EMS weld bead is gentler and smoother, indicating that the quality of the GATW weld bead can be significantly improved by the application of an electromagnetic field.

The microstructure of the weld bead and HAZ of the solution-quenched state MAR-M247 superalloy welded without solder is also observed (the image of marked 1 and 2 in Fig. 7). From the image of marked 1 in Fig. 7, it can be seen that the Chinese script shaped carbides in the weld bead molten zone of the GATW specimen are up to $50 \mu \mathrm{m}$ in size, while those in the weld bead zone of the GATW + EMS specimen are significantly down to $10-15 \mu \mathrm{m}$ (as shown in Fig. 7 within marked 2). This result indicates that the application of an external magnetic field can help to refine the Chinese script shape carbides in the molten zone of the weld bead. In addition, the composition of the Chinese script shaped carbides in the weld bead is analyzed by EPMA, and the results revealed them to be mainly comprised of $\mathrm{Ti}$, Ta, and Hf (Fig. 8).

Figure 9 shows a cross-section of the solution-quenched state MAR-M247 superalloy welded with BOP welding. As can be observed in the figure, the weld bead height of the GAWT and GATW + EMS specimens is $1.48 \mathrm{~mm}$, but the weld bead widths of the GAWT and GATW + EMS specimens are $6.91 \mathrm{~mm}$ and 5.61 $\mathrm{mm}$, respectively, indicating that GAWT + EMS can effectively narrow the weld bead width and subsequently increase the weld bead formation coefficient from 4.66 to 3.79. The lower the weld bead formation coefficient, the better the repair quality.

Figure 10 shows a cross-section of the microstructure of the GATW and GATW + EMS bead-on-plate weld bead and HAZ of the solution-quenched MAR-M247 superalloy welded with 625 solder. The width of the columnar grains of GATW is $25 \mu \mathrm{m}$, while that of GATW + EMS is only $15 \mu \mathrm{m}$. Notably, coarse grains $200 \mu \mathrm{m}$ in size are observed in the HAZ of the GATW specimen, but not in that of the GATW + EMS specimen, indicating that the application of magnetic field can lead to an effective reduction of the grain size in the molten zone and HAZ. 


\subsection{BOP three-pass overlay welding}

Figure 11 shows the appearance and X-ray inspection analysis chart of the GATW and GATW + EMS specimens after three-pass overlay welding. As can be observed from the figure, the width of the weld bead with a coverage of $50 \%$ after three-pass overlay welding is $9 \mathrm{~mm}$, while that for GATW + EMS is clearly narrower, $7.7 \mathrm{~mm}$. X-ray analysis reveals the presence of clear cracks in the GATW, but not in the GATW + EMS specimens, indicating that GATW + EMS can effectively reduce the generation of welding hot cracks in the MAR-M247 superalloy.

The pattern of cracks produced by GATW three-pass overlay welding (Fig. 12) is observed using metallographic microscopy. It can be seen that Chinese script shaped carbides liquefy around the cracks during welding solidification, supposedly one of the main causes of welding cracks. The SEM images with EDS analysis (as shown Fig. 13) also show the cracks to be filled with Chinese script shaped carbides.

\subsection{Impact of EMS on the weld bead temperature}

Figure 14 shows the instantaneous temperature of the HAZ during the GATW and GATW + EMS welding process measured using an infrared thermometer. As can be oved from the figure, the effect of the arc on the instantaneous temperature of the HAZ of the MAR-M247 specimen during the welding process of GATW is observed at $\sim 1600^{\circ} \mathrm{C}$, while the instantaneous temperature during GATW + EMS can drop to $1113^{\circ} \mathrm{C}$, indicating that the effect of the heat input source of the arc on the HAZ can be considerably reduced by the application of the external electromagnetic field speeding up the cooling rate of the weld pool. It is speculated that this is the main reason for the refinement of the carbide size and grain size in the HAZ.

\subsection{Analysis of mechanical properties in V-shape butt welding tests}

\subsubsection{Hardness}

The hardness of v-butt welded specimens is measured along the center line of the welding cross section of the MAR-M247 superalloy welded with GATW and GATW + EMS. Figure 15 shows the results obtained from hardness measurements. As shown in Fig. 16, the GATW and GATW + EMS welded joint can be divided into three zones: the weld zone, the heat affected zone, and the base metal. The hardness of the weld zone of the GATW and GATW + EMS specimen exhibits the same trend. The hardness is lowest in the center of the weld zone center and increases with the distance from the center. High hardness is still exhibited in the base metal zone because it is far away from the weld zone and not much affected by the welding heat input source. Note that the hardness values of the HAZ and weld zone center of the GATW + EMS specimen are significantly greater than those produced by GATW. In addition, the results revealed that the GATW + EMS hardness is better than that of GATW because GATW + EMS can effectively refine the grains in the HAZ and the weld zone, reflecting the grain strengthening effect. 


\subsubsection{Tensile properties}

Figure 16 shows the tensile mechanical properties of the GATW and GATW + EMS welded specimens of the MAR-M247 superalloy after heat treatment. The Young's modulus, yield strength, tensile strength, and ductility of the GATW-welded specimens are $191 \mathrm{GPa}, 785 \mathrm{MPa}, 891 \mathrm{MPa}$, and 2.5\%, respectively, while those of the GATW + EMS-welded specimens are $199 \mathrm{GPa}, 800 \mathrm{MPa}, 930 \mathrm{MPa}$, and 3.4\%, respectively. The results revealed that the magnetic field can effectively improve the tensile mechanical properties of GATW weldments, which match the Engine Material Specification EMS-55447 [48].

\subsubsection{Tensile fracture surface}

Figure 17 shows the tensile fracture surfaces of the GATW and GATW + EMS-welded specimens of the MAR-M247 superalloy. As can be seen in the figure, there is a clearly observable cleavage surface on the fracture surface of the GATW-welded specimen, while the fracture surface of the GATW + EMS specimen is mainly a dimpled structure, indicating that the ductility of the GATW + EMS-welded specimen is better than that of the GATW-welded specimen, which is consistent with the results observed from the tensile property analysis.

\section{Conclusion}

1. The as-cast state MAR-M247 matrix is mainly composed of the austenite $y$ phase, and the $\gamma^{\prime}$ phase, Chinese script shaped carbides, $y-\gamma^{\prime}$ eutectic structures, and thick-plate $\gamma^{\prime}$. These carbides are mainly composed of $\mathrm{Ti}, \mathrm{Ta}$, and $\mathrm{Hf}$, which are widely and evenly distributed in the MAR-M247 matrix. Furthermore, the solid-solution heat treatment does not lead to any significant change in the morphology of the Chinese script shaped carbides in the MAR-M247 alloy.

2. The results revealed that without the application of the electromagnetic field, a bell-shaped GATW arc is observed, and carbides in the HAZ of the GATW weld bead are easily liquefied due to the input of considerable heat during welding, thereby leading to welding cracks. Results also revealed that GATW + EMS exhibited a meteor-shaped arc, which can considerably decrease the weld bead temperature, improve the WRFF coefficient, and reduce the generation of hot cracks.

3. GATW + EMS can dramatically reduce the effect of the arc heat input source on the welded workpieces, and can further refine the size of carbides in the weld bead as well as the size of grains in the HAZ, effectively improving the mechanical properties.

\section{Declarations}

Funding (information that explains whether and by whom the research was supported)

Not applicable

Conflicts of interest/Competing interests (include appropriate disclosures) 
I would like to declare on behalf of my co-authors that the work described was original research that has not been published previously, and not under consideration for publication elsewhere, in whole or in part. To the best of our knowledge, the named authors have no conflict of interest, financial or otherwise.

Availability of data and material (data transparency)

Not applicable

Code availability (software application or custom code)

Not applicable

Ethics approval (include appropriate approvals or waivers)

Not applicable

Consent to participate (include appropriate statements)

Not applicable

Consent for publication (include appropriate statements)

Not applicable

Authors' contributions (optional: please review the submission guidelines from the journal whether statements are mandatory)

Dr. Tzeng Yu-Chih: Conceptualization, Methodology, Investigation, Supervision, Funding acquisition, Validation, Writing - review \& editing. Dr. Lu Cheng-Yu: Conceptualization, Investigation \& Validation. All authors equally contributed the overall manuscript. Dr. Chen Ren-Yu: Conceptualization, Investigation, Methodology, Writing - original draft, Writing - review \& editing.

\section{References}

1. M. Morinaga, N. Yukawa, H. Adachi, H. Ezaki, (1984) New PHACOMP and its applications to alloy design, Superalloys 1984, 523-532. https://doi.org/10.7449/1984/Superalloys_1984_523_532

2. M. Kvapilova, J. Dvorak, P. Kral, K. Hrbacek, V. Sklenicka, (2019) Creep behaviour and life assessment of a cast nickel-base superalloy MAR-M247, High Temperature Materials and Processes, 38(2019), 590-600. https://doi.org/10.1515/htmp-2019-0006

3. P.R.S. Azevedo e Silva, R. Baldan, C.A. Nunes, G.C. Coelho, A.M.d.S. Costa, (2013) Solution heattreatment of Nb-modified MAR-M247 superalloy, Materials Characterization, 75, 214219. https://doi.org/10.1016/j.matchar.2012.11.006

4. H.S. Whitesell, R.A. Overfelt, (2001) Influence of solidification variables on the microstructure, macrosegregation, and porosity of directionally solidified Mar-M247, Materials Science and 
Engineering: A, 318(1-2), 264-276. https://doi.org/10.1016/s0921-5093(01)01264-3

5. M. Okada, M. Tsutsumi, T. Kitamura, R. Ohtani, (2010) Initiation and Growth of Small Cracks in Directionally Solidified Mar-M247 under Creep-Fatigue. Part I: Effect of Microstructure, Fatigue \& Fracture of Engineering Materials \& Structures, 21(6), 741-750. https://doi.org/10.1046/j.14602695.1998.00540.x

6. H. Bor, C. Chao, C. Ma, (1997) The influence of magnesium on carbide characteristics and creep behavior of the Mar-M247 superalloy, Scripta materialia, 38(2), 329335. https://doi.org/0.1016/S1359-6462(97)00444-2

7. R. Baldan, P.R.S. Azevedo e Silva, C.A. Nunes, G.C. Coelho, (2013) Aging of a New Niobium-Modified MAR-M247 Nickel-Based Superalloy, Journal of Materials Engineering and Performance, 22(8), 23372342. https://doi.org/10.1007/s11665-013-0531-1

8. H.Y. Bor, C.N. Wei, R.R. Jeng, P.Y. Ko, (2008) Elucidating the effects of solution and double ageing treatment on the mechanical properties and toughness of MAR-M247 superalloy at high temperature, Materials Chemistry and Physics, 109(2-3), 334-

341. https://doi.org/10.1016/j.matchemphys.2007.11.041

9. Y. Hagedorn, J. Risse, W. Meiners, N. Pirch, K. Wissenbach, R. Poprawe, Processing of nickel based superalloy MAR M-247 by means of High Temperature-Selective Laser Melting (HT-SLM), Proceedings of the 6th International Conference on Advanced Resarch in Virtual and Rapid Prototyping, 2013, pp 291-295. https://doi.org/10.1201/b15961-54

10. M. Kaufman, (1984) Properties of cast Mar-M-247 for turbine blisk applications, Superalloys 1984, 43-52. https://doi.org/10.7449/1984/Superalloys_1984_43_52

11. M.-c. Liu, G.-m. Sheng, H.-j. He, Y.-j. Jiao, (2017) Microstructural evolution and mechanical properties of TLP bonded joints of Mar-M247 superalloys with Ni-Cr-Co-W-Ta-B interlayer, Journal of Materials Processing Technology, 246, 245-251. https://doi.org/10.1016/j.jmatprotec.2017.03.021

12. M. Rahimian, S. Milenkovic, I. Sabirov, (2013) Microstructure and hardness evolution in MAR-M247 Ni-based superalloy processed by controlled cooling and double heat treatment, Journal of Alloys and Compounds, 550, 339-344. https://doi.org/10.1016/j.jallcom.2012.10.129

13. M.V. Nathal, L.J. Ebert, (1985) The influence of cobalt, tantalum, and tungsten on the microstructure of single crystal nickel-base superalloys, Metallurgical Transactions A, 16(10), 18491862. https://doi.org/10.1007/bf02670372

14. K.L. Gasko, G.M. Janowski, B.J. Pletka, (1988) The influence of $y-y^{\prime}$ eutectic on the mechanical properties of conventionally cast MAR-M247, Materials Science and Engineering: A, 104, 18. https://doi.org/10.1016/0025-5416(88)90400-4

15. R. Baldan, R.L.P. da Rocha, R.B. Tomasiello, C.A. Nunes, A.M. da Silva Costa, M.J.R. Barboza, G.C. Coelho, R. Rosenthal, (2013) Solutioning and Aging of MAR-M247 Nickel-Based Superalloy, Journal of Materials Engineering and Performance, 22(9), 2574-2579. https://doi.org/10.1007/s11665-0130565-4 
16. J.-H. Liao, H.-Y. Bor, C.-N. Wei, C.-G. Chao, T.-F. Liu, (2012) Influence of microstructure and its evolution on the mechanical behavior of modified MAR-M247 fine-grain superalloys at $871^{\circ} \mathrm{C}$, Materials Science and Engineering: A, 539, 93-100. https://doi.org/10.1016/j.msea.2012.01.059

17. 17. S. Milenkovic, I. Sabirov, J. Llorca, (2012) Effect of the cooling rate on microstructure and hardness of MAR-M247 Ni-based superalloy, Materials Letters, 73, 216219. https://doi.org/10.1016/j.matlet.2012.01.028

18. Ł. Rakoczy, M. Grudzień, A. Zielińska-Lipiec, (2018) Contribution of microstructural constituents on hot cracking of MAR-M247 nickel based superalloy, Archives of Metallurgy and Materials, 63, https://doi.org/10.24425/118926

19. S.R. Yeratapally, J.D. Hochhalter, T.J. Ruggles, M.D. Sangid, (2017) Investigation of fatigue crack incubation and growth in cast MAR-M247 subjected to low cycle fatigue at room temperature, International Journal of Fracture, 208(1-2), 79-96. https://doi.org/10.1007/s10704-017-0213-3

20. S. Eckmann, C. Schweizer, (2017) Characterization of fatigue crack growth, damage mechanisms and damage evolution of the nickel-based superalloys MAR-M247 CC (HIP) and CM-247 LC under thermomechanical fatigue loading using in situ optical microscopy, International Journal of Fatigue, 99, 235-241. https://doi.org/10.1016/j.ijfatigue.2017.01.015

21. M. Reza Abedi, S. Hamed; R. Hossein, (2016) The Effect of Repair Welding Number on Microstructure of Hastelloy X Fabricated via TIG Process, International Journal of Materials Science and Applications, 5(2), 43-48. https://doi.org/10.11648/j.ijmsa.20160502.12

22. Q. Wang, D.L. Sun, Y. Na, Y. Zhou, X.L. Han, J. Wang, (2011) Effects of TIG Welding Parameters on Morphology and Mechanical Properties of Welded Joint of Ni-base Superalloy, Procedia Engineering, 10, 37-41. https://doi.org/10.1016/j.proeng.2011.04.009

23. Z. Li, S.L. Gobbi, K.H. Richter, (1997) Autogenous welding of Hastelloy X to Mar-M 247 by laser, Journal of Materials Processing Technology, 70(1-3), 285-292. https://doi.org/10.1016/s09240136(97)02939-7

24. B. Böttger, M. Apel, T. Jokisch, A. Senger, Phase-field study on microstructure formation in Mar-M247 during electron beam welding and correlation to hot cracking susceptibility, IOP Conference Series: Materials Science and Engineering, 2020, IOP Publishing, p 012072. https://doi.org/10.1088/1757899X/861/1/012072

25. O.N. Senkov, D.W. Mahaffey, S.L. Semiatin, C. Woodward, (2014) Inertia Friction Welding of Dissimilar Superalloys Mar-M247 and LSHR, Metallurgical and Materials Transactions A, 45(12), 55455561. https://doi.org/10.1007/s11661-014-2512-x

26. D.W. Mahaffey, O.N. Senkov, R. Shivpuri, S.L. Semiatin, (2016) Effect of Process Variables on the Inertia Friction Welding of Superalloys LSHR and Mar-M247, Metallurgical and Materials Transactions A, 47(8), 3981-4000. https://doi.org/10.1007/s11661-016-3600-x

27. H. Wu, Y. Chang, L. Lu, J. Bai, (2017) Review on magnetically controlled arc welding process, The International Journal of Advanced Manufacturing Technology, 91(9-12), 42634273. https://doi.org/10.1007/s00170-017-0068-9 
28. S.Y. Jiang, X.W. Wang, H.M. Chen, P. Liu, The impact of adscititious longitudinal magnetic field on C02 welding process, Advanced Materials Research, 2012, Trans Tech Publ, pp 1447-

1450. https://doi.org/10.4028/www.scientific.net/AMR.538-541.1447

29. T. Watanabe, H. Nakamura, K. Ei, (2010) Grain refinement by TIG welding with electromagnetic stirring - a study of solidification control of austenitic stainless steel weld metal, Welding International, 3(4), 312-317. https://doi.org/10.1080/09507118909447649

30. Y.C. Lim, X. Yu, J.H. Cho, J. Sosa, D.F. Farson, S.S. Babu, S. McCracken, B. Flesner, (2013) Effect of magnetic stirring on grain structure refinement Part 2 - Nickel alloy weld overlays, Science and Technology of Welding and Joining, 15(5), 400-

406. https://doi.org/10.1179/136217110x12720264008231

31. S.-L. Jeng, D.-P. Su, J.-T. Lee, J.-Y. Huang, (2020) The Impact of EMS on the Temperature Fluctuations, Appearance, and Microstructure of GTA Stainless Steel Welds, Metals, 10(1), 118. https://doi.org/10.3390/met10010118

32. Y. Liu, Q. Sun, J. Liu, S. Wang, J. Feng, (2015) Effect of axial external magnetic field on cold metal transfer welds of aluminum alloy and stainless steel, Materials Letters, 152, 29-

31. https://doi.org/10.1016/j.matlet.2015.03.077

33. S.-L. Jeng, D.-P. Su, J.-T. Lee, J.-Y. Huang, (2018) Effects of Electromagnetic Stirring on the Cast Austenitic Stainless Steel Weldments by Gas Tungsten Arc Welding, Metals, 8(8), 630. https://doi.org/10.3390/met8080630

34. T. Tsang, D. Savage, (1971) The effect of arc oscillation in either transverse or longitudinal direction has beneficial effect on the fusion zone microstructure and tends to reduce sensitivity in hot cracking, Welding J, 50(11), 777-786.

35. R. Chen, P. Jiang, X. Shao, G. Mi, C. Wang, (2017) Effect of static magnetic field on microstructures and mechanical properties of laser-MIG hybrid welding for 304 stainless steel, The International Journal of Advanced Manufacturing Technology, 91(9-12), 3437-

3447. https://doi.org/10.1007/s00170-017-0006-x

36. M. Malinowski-Brodnicka, G. Den Ouden, W. Vink, (1990) Effect of electromagnetic stirring on GTA welds in austenitic stainless steel, Welding journal, 2(2), 52s-59s.

37. G.R.M. Arturo, L.M.V. Hugo, G.H. Rafael, B.B. Egberto, G.S.J. Antonio, (2015) Electrochemical Characterization of AISI 2205 Duplex Stainless Steel Welded Joints with Electromagnetic Interaction, Procedia Materials Science, 8, 950-958. https://doi.org/10.1016/j.mspro.2015.04.156

38. F.F. Curiel, R. García, V.H. López, J. González-Sánchez, (2011) Effect of magnetic field applied during gas metal arc welding on the resistance to localised corrosion of the heat affected zone in AISI 304 stainless steel, Corrosion Science, 53(7), 2393-2399. https://doi.org/10.1016/j.corsci.2011.03.022

39. M. Shoichi, M. Yukio, T. Koki, T. Yasushi, M. Yukinori, M. Yusuke, (2013) Study on the application for electromagnetic controlled molten pool welding process in overhead and flat position welding, Science and Technology of Welding and Joining, 18(1), 38-

44. https://doi.org/10.1179/1362171812y.0000000070

Page $11 / 28$ 
40. V.V. Avilov, A. Gumenyuk, M. Lammers, M. Rethmeier, (2013) PA position full penetration high power laser beam welding of up to $30 \mathrm{~mm}$ thick AlMg3 plates using electromagnetic weld pool support, Science and Technology of Welding and Joining, 17(2), 128-

133. https://doi.org/10.1179/1362171811y.0000000085

41. B.P. Pearce, H.W. Kerr, (1981) Grain refinement in magnetically stirred GTA welds of aluminum alloys, Metallurgical Transactions B, 12(3), 479-486. https://doi.org/10.1007/bf02654317

42. W.D. Griffiths, D.G. McCartney, (1997) The effect of electromagnetic stirring on macrostructure and macrosegregation in the aluminium alloy 7150, Materials Science and Engineering: A, 222(2), 140148. https://doi.org/10.1016/s0921-5093(96)10527-x

43. Z.H. Gao, J. Xu, Z.F. Zhang, M.O. Tang, Effect of annular electromagnetic stirring on microstructure and mechanical property of 7075 aluminium alloy, Materials Science Forum, 2013, Trans Tech Publ, pp 75-81. https://doi.org/10.4028/www.scientific.net/MSF.749.75

44. Y. Chen, F.F. Sui, K.L. Cong, X.Q. Yan, G.Y. Zhang, S.K. Guan, Effects of shielding gas and magnetic field on characteristics of AZ31 magnesium alloy by TIG welding, Materials Science Forum, 2012, Trans Tech Publ, pp 1186-1196. https://doi.org/10.4028/www.scientific.net/MSF.704-705.1186

45. Q. Yao, Z. Luo, Y. Li, F.Y. Yan, R. Duan, (2014) Effect of electromagnetic stirring on the microstructures and mechanical properties of magnesium alloy resistance spot weld, Materials \& Design, 63, 200207. https://doi.org/10.1016/j.matdes.2014.06.004

46. X.-I. Zhang, T.-j. Li, H.-t. Teng, S.-s. Xie, J.-z. Jin, (2008) Semisolid processing AZ91 magnesium alloy by electromagnetic stirring after near-liquidus isothermal heat treatment, Materials Science and Engineering: A, 475(1-2), 194-201. https://doi.org/10.1016/j.msea.2007.04.049

47. Y. Chen, L. Zhang, W. Liu, G. Wu, W. Ding, (2016) Preparation of Mg-Nd-Zn-(Zr) alloys semisolid slurry by electromagnetic stirring, Materials \& Design, 95, 398-409. https://doi.org/10.1016/j.matdes.2016.01.131

48. H.Y. Bor, C.G. Chao, C.Y. Ma, (1999) The effects of Mg microaddition on the mechanical behavior and fracture mechanism of MAR-M247 superalloy at elevated temperatures, Metallurgical and Materials Transactions A, 30(3), 551-561. https://doi.org/10.1007/s11661-999-0047-3

\section{Figures}




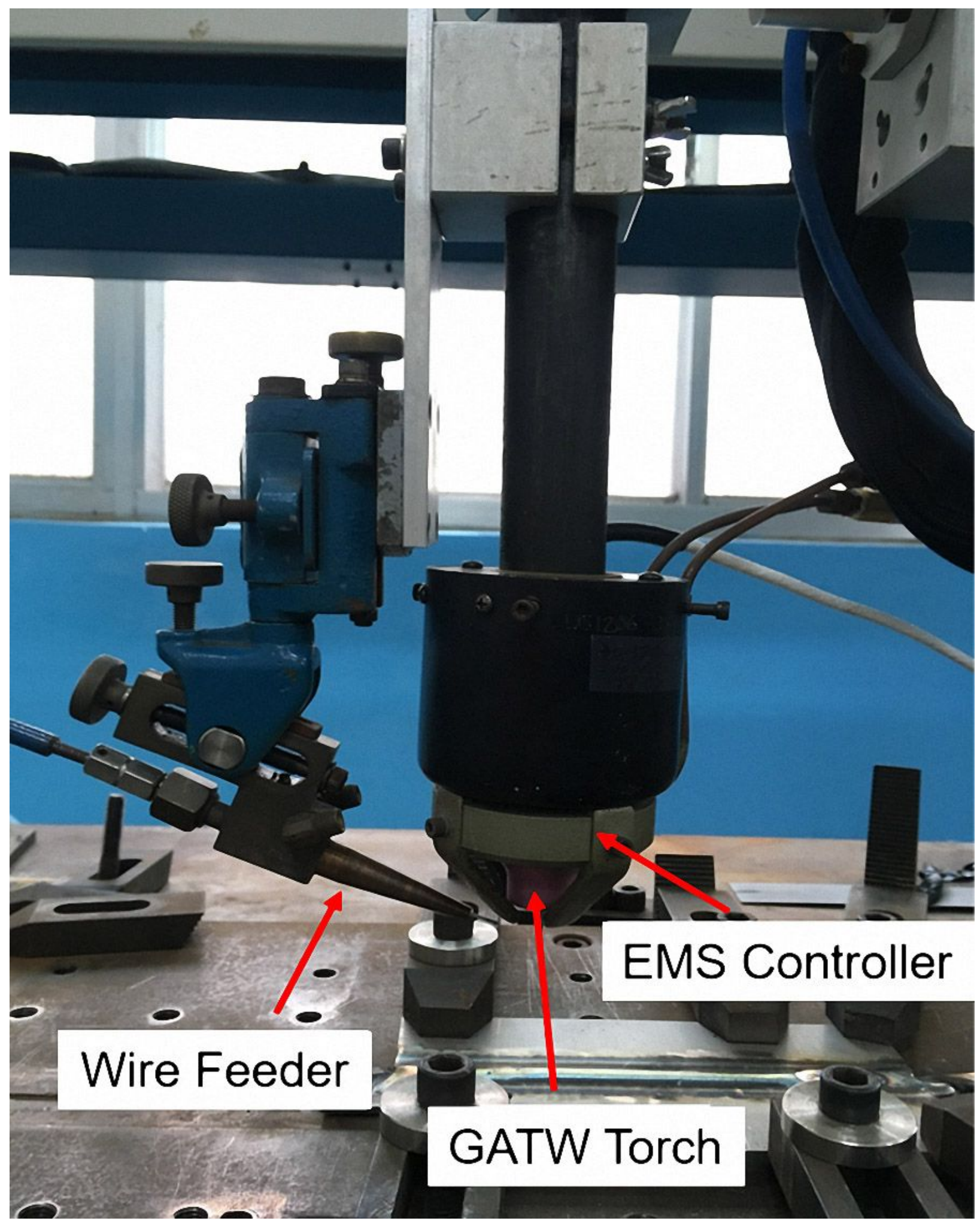

Figure 1

Schematic representation illustrating the assistance of the external magnetic field to GATW welding. 

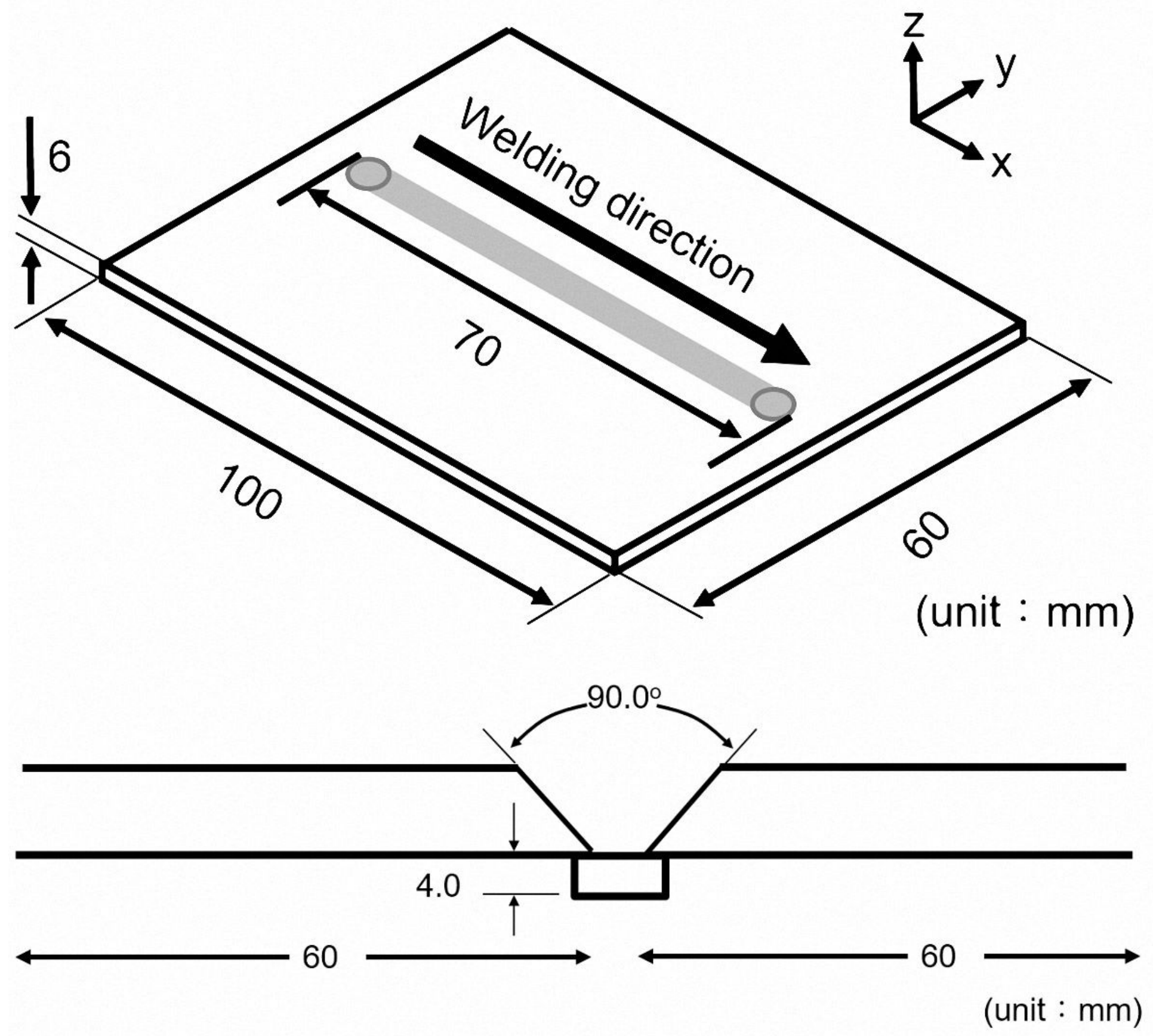

Figure 2

Welding methods: (a) bead-on-plate welding (BOP); (b) v-butt welding. 

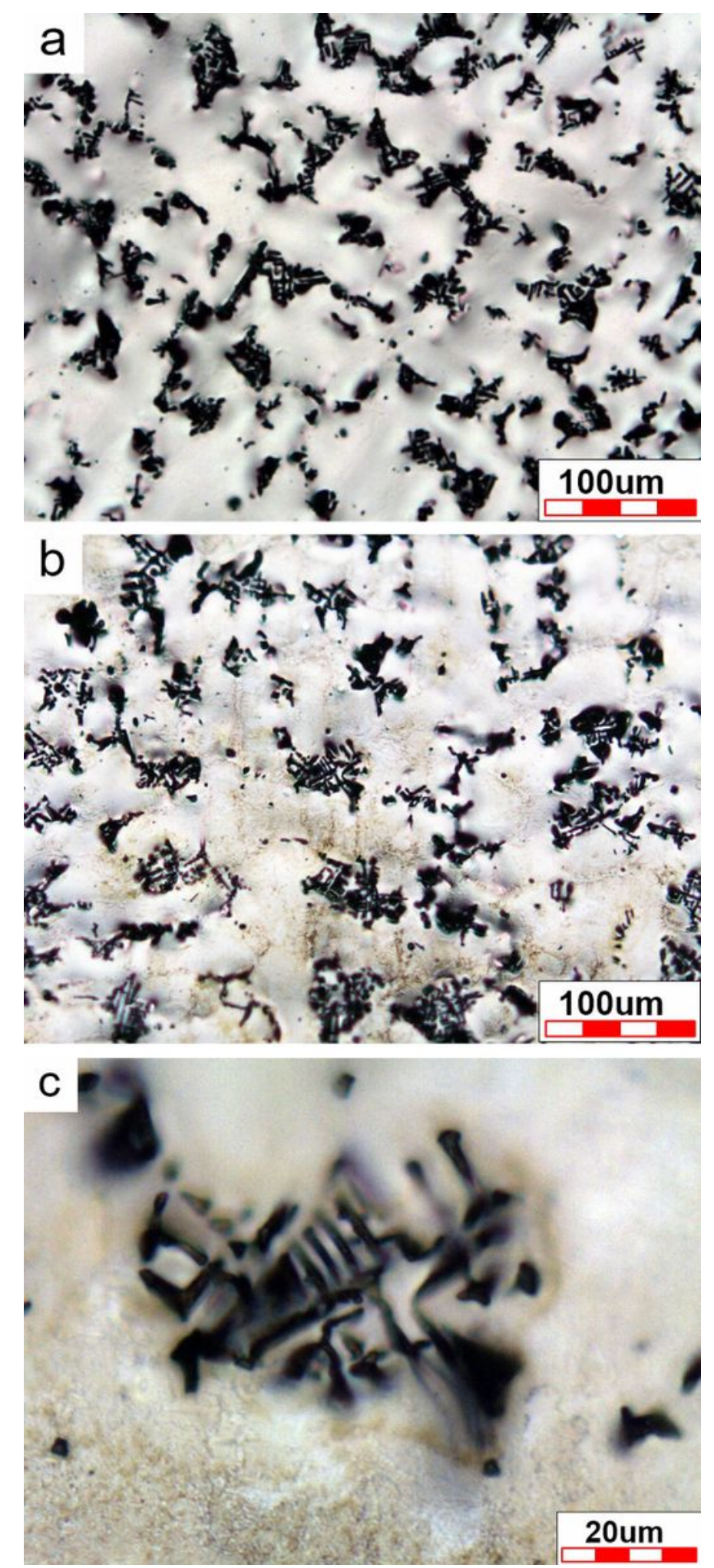

Figure 3

Microstructure of the as-cast and solution-quenched state of the MAR-M247 nickel-based superalloy 

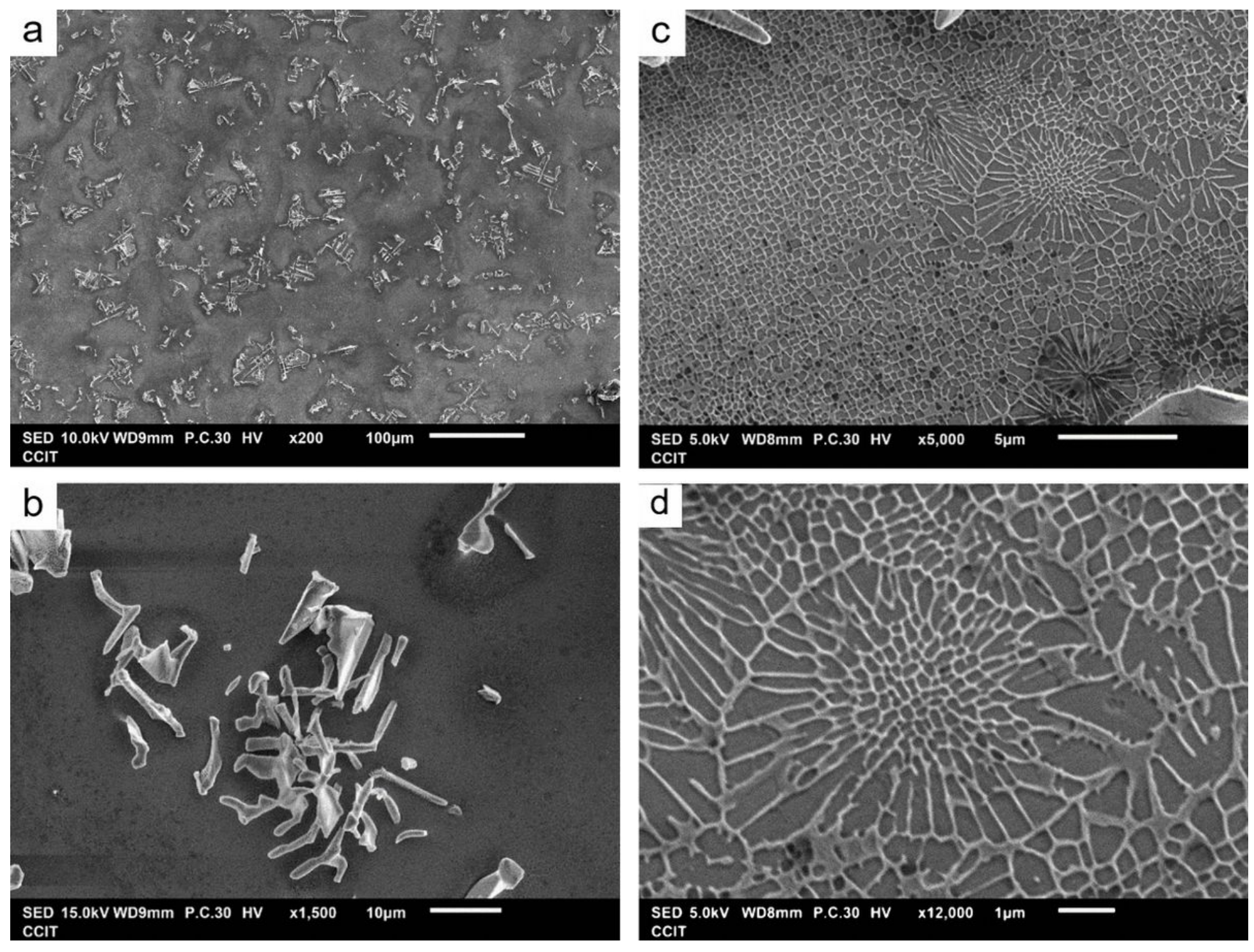

Figure 4

MAR-M247: (a) as-cast; (b) solution-quenched; and (c) Chinese script shaped carbide microstructure. 

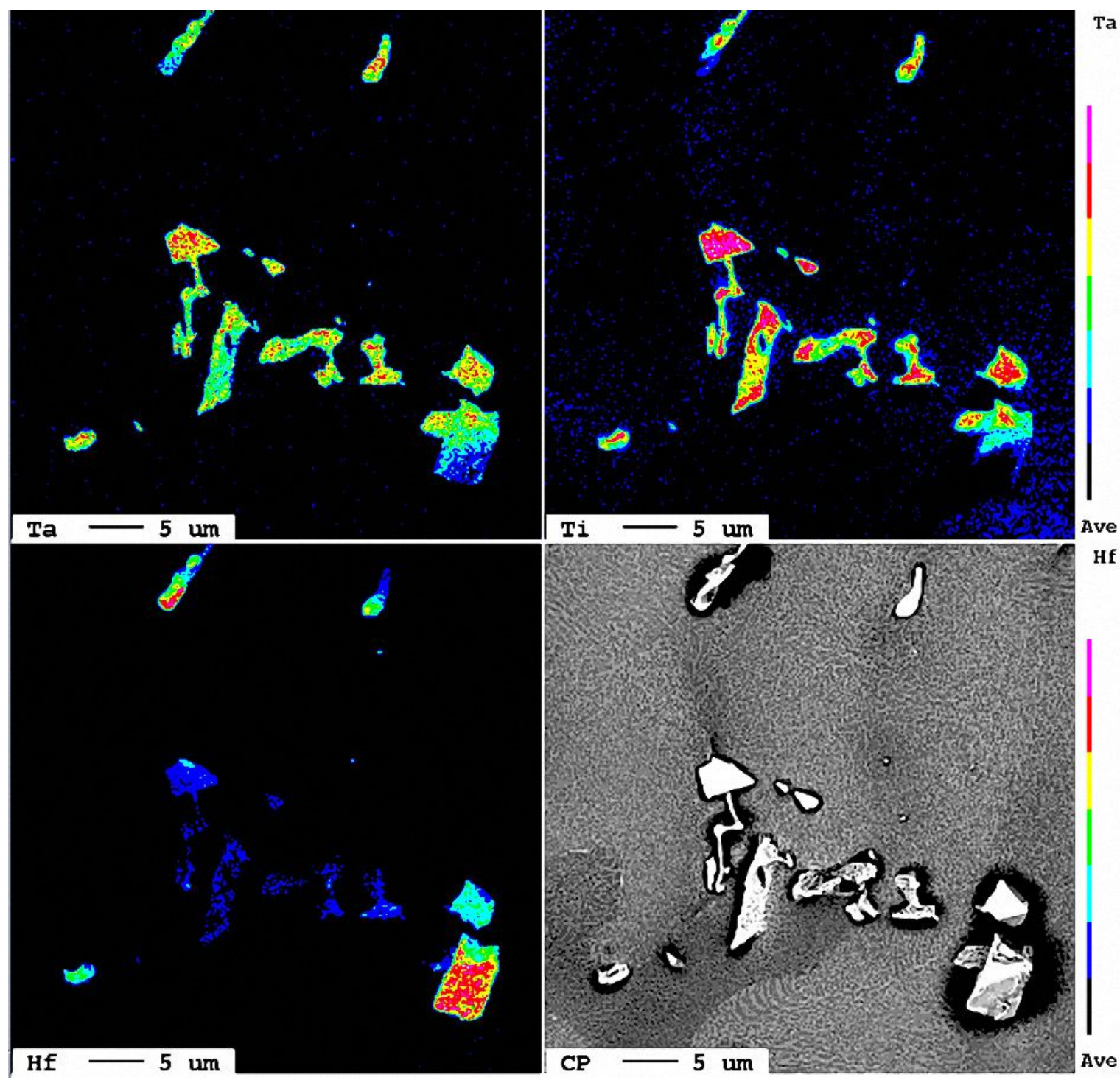

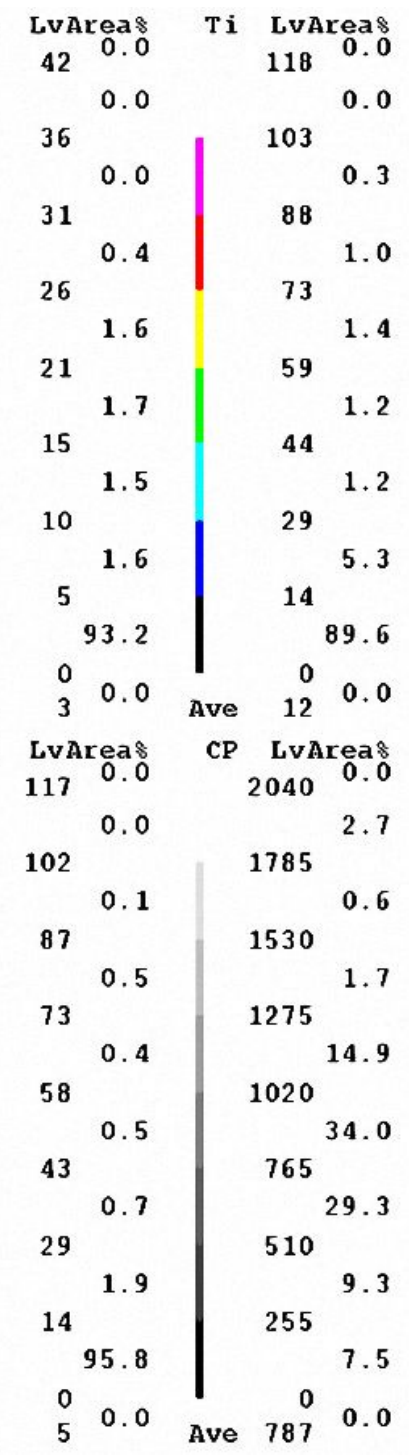

Figure 5

SEM microstructure of the solution-quenched MAR-M247 superalloy: (a) basic microstructure; (b) Chinese script shaped carbide; (c) thick-plate microstructure of the $\gamma^{\prime}$ phase; (d) rose-shaped $\gamma-\gamma^{\prime}$ eutectic structure. 


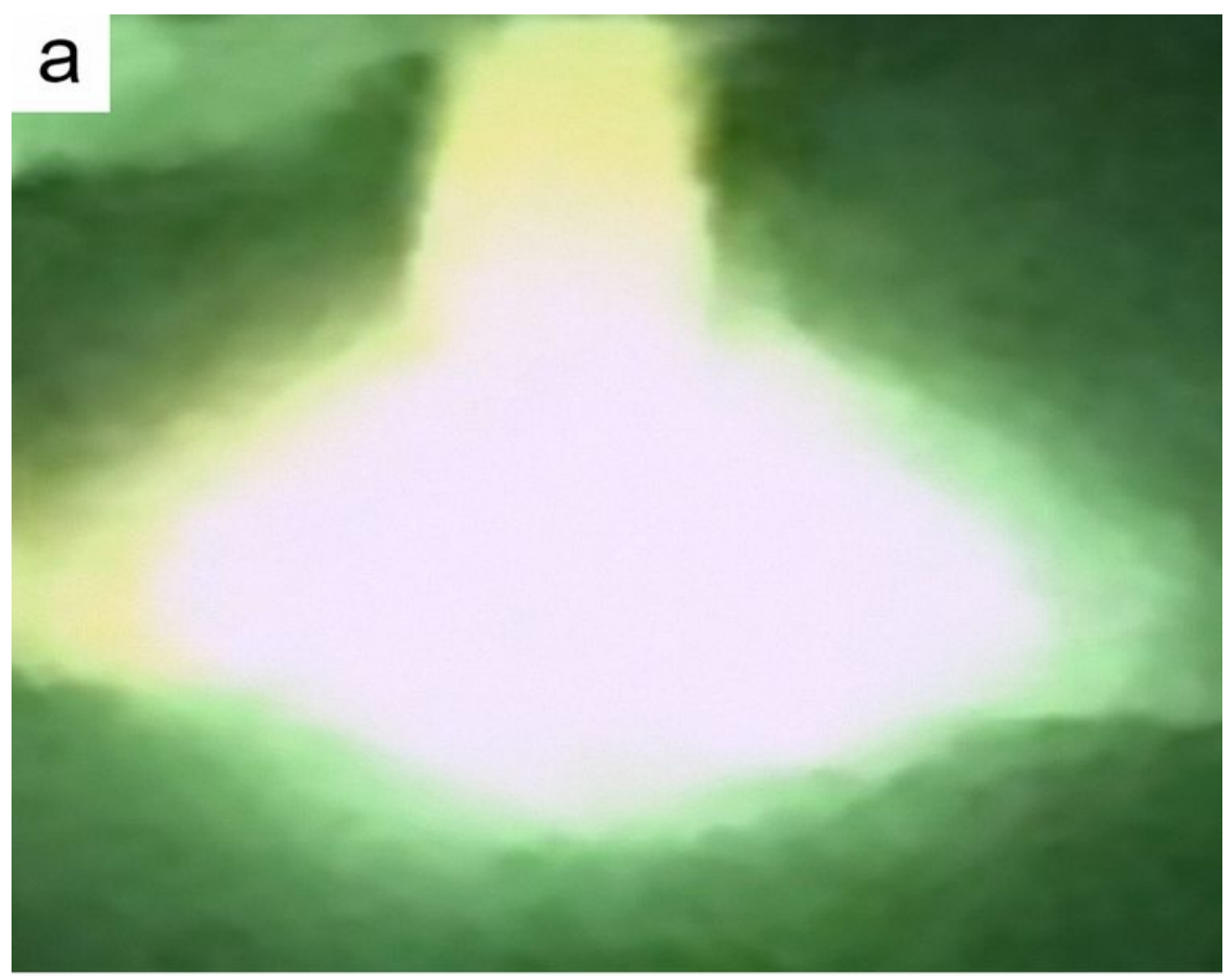

b

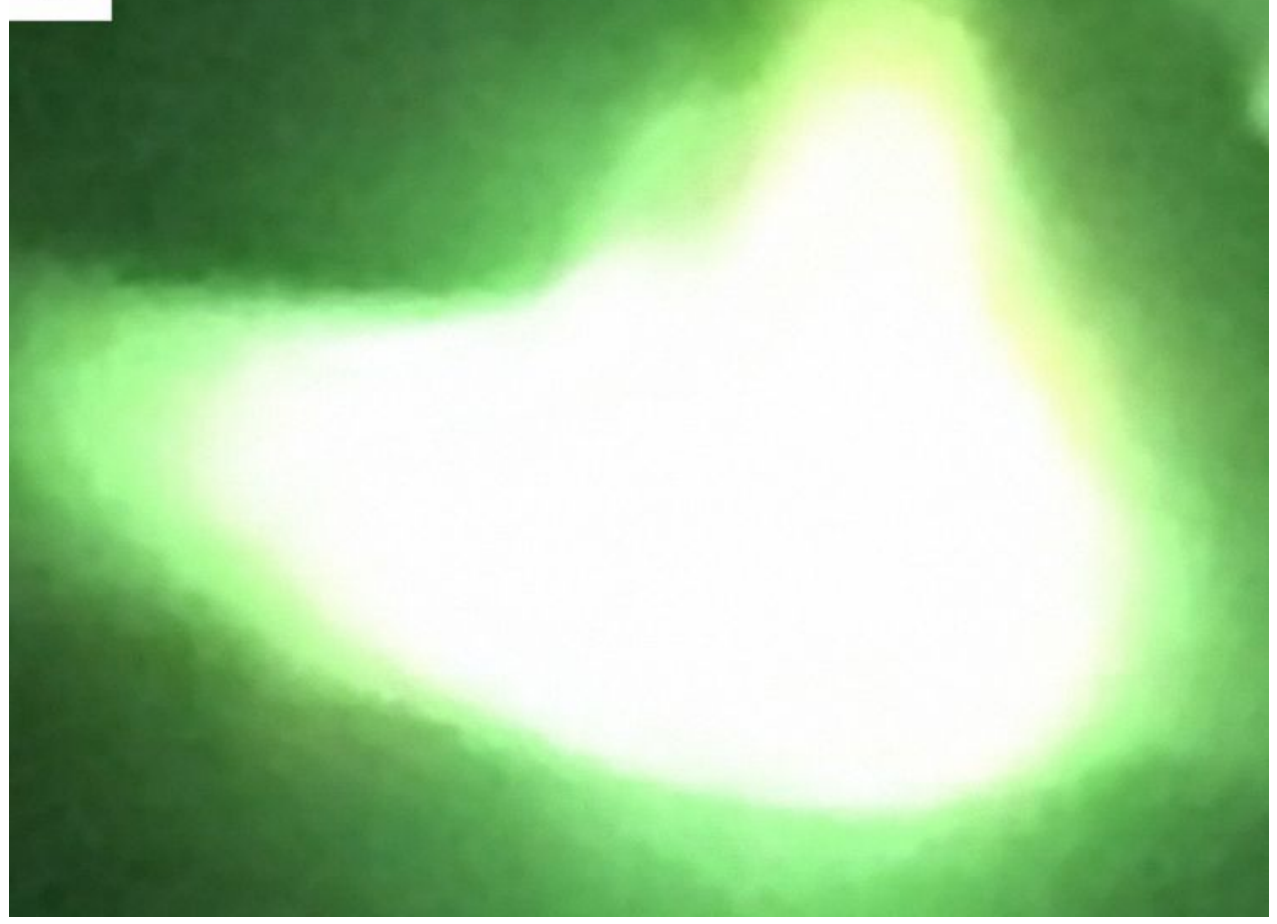

Figure 6

EPMA compositional analysis of Chinese script shaped carbides. 

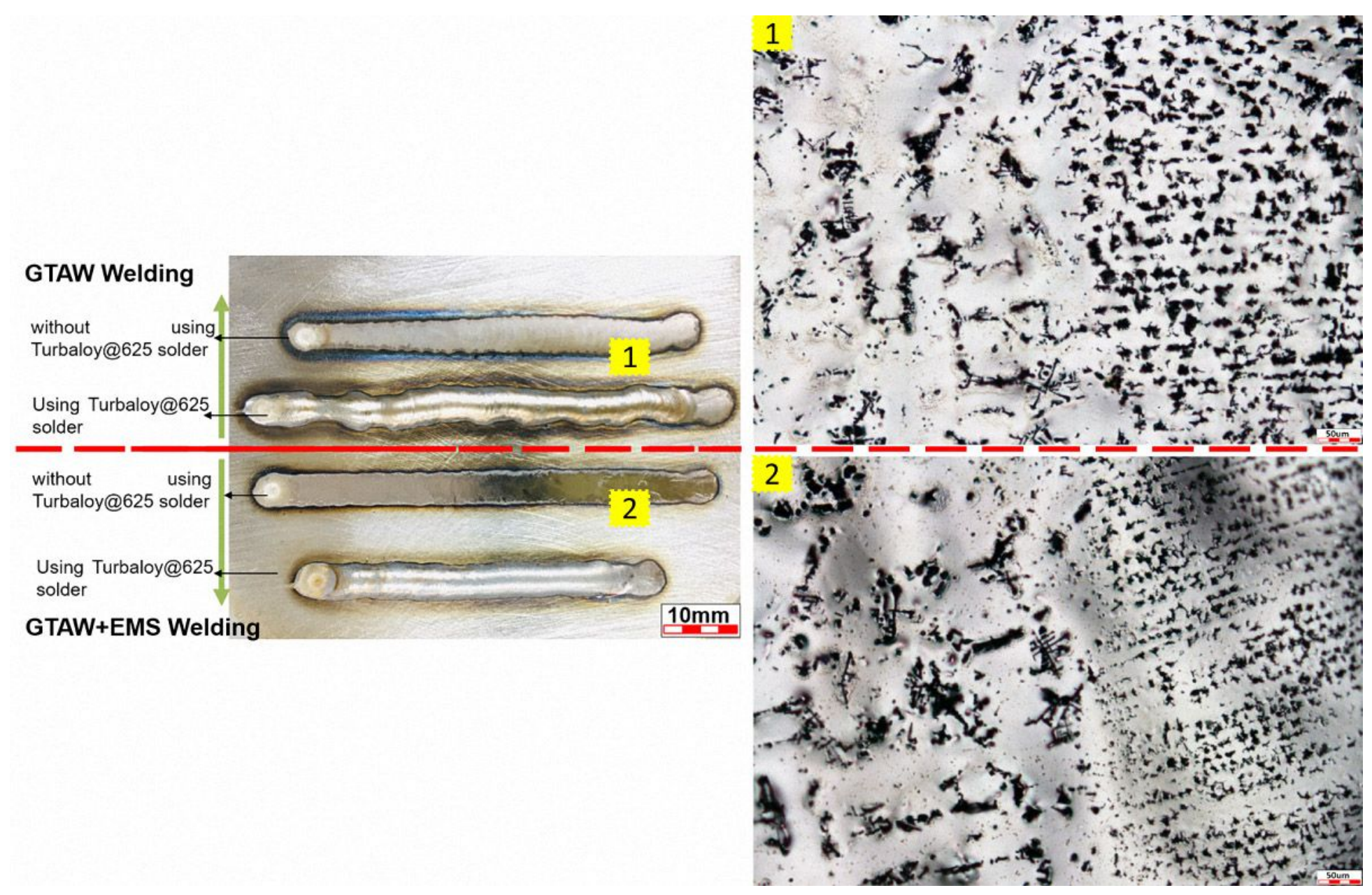

Figure 7

Solution-quenched MAR-M247 with Bead-on-plate welding and the microstructure of the weld bead and HAZ zone without using a Turbalay@625 solder. Marked 1 in the figure is the OM image of the GTAW. Marked 2 in the figure is the OM image of the GTAW+EMS. 


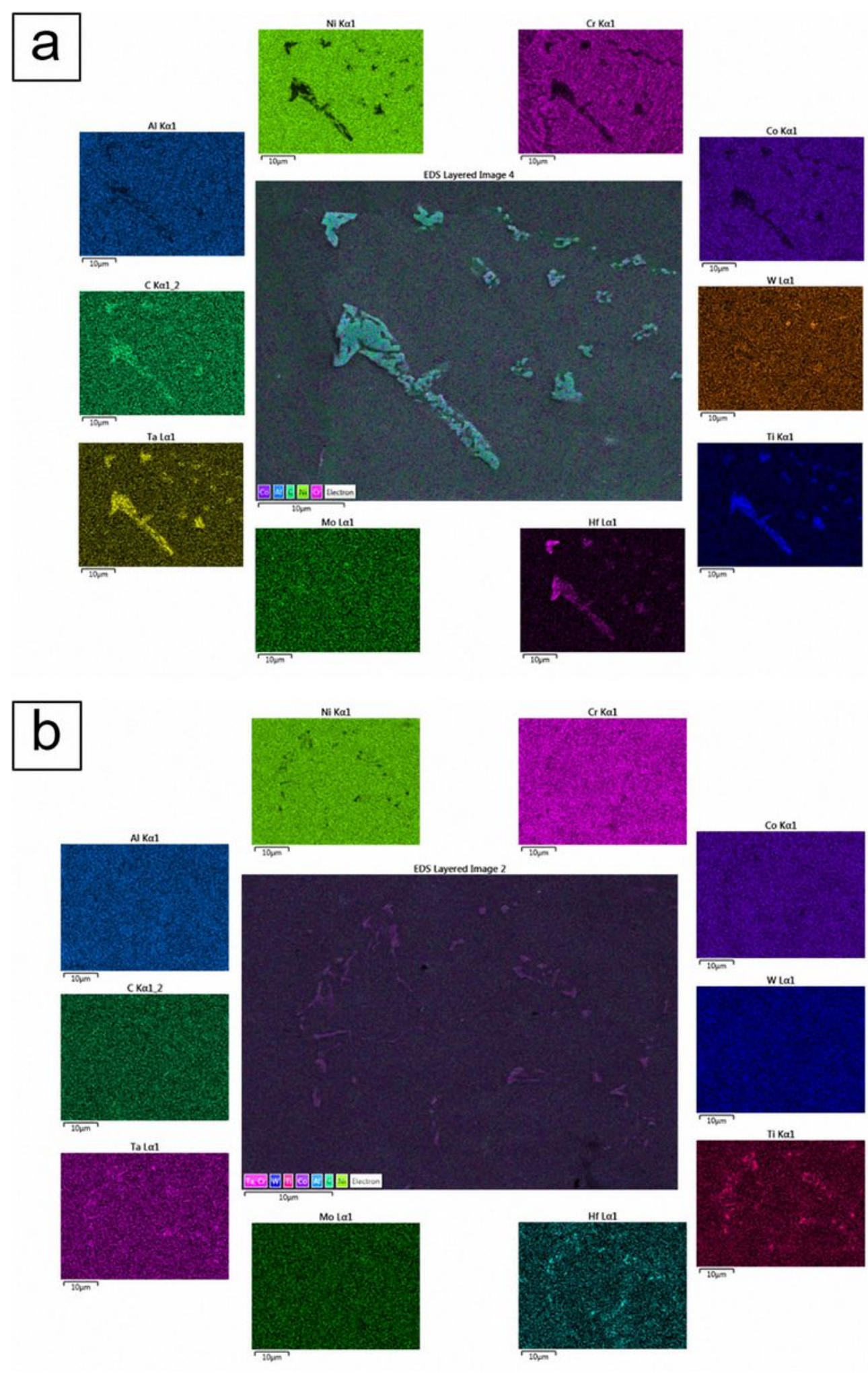

Figure 8

Cross section of the weld bead of the solution-quenched MAR-M247 superalloy welded by the bead-onplate. 

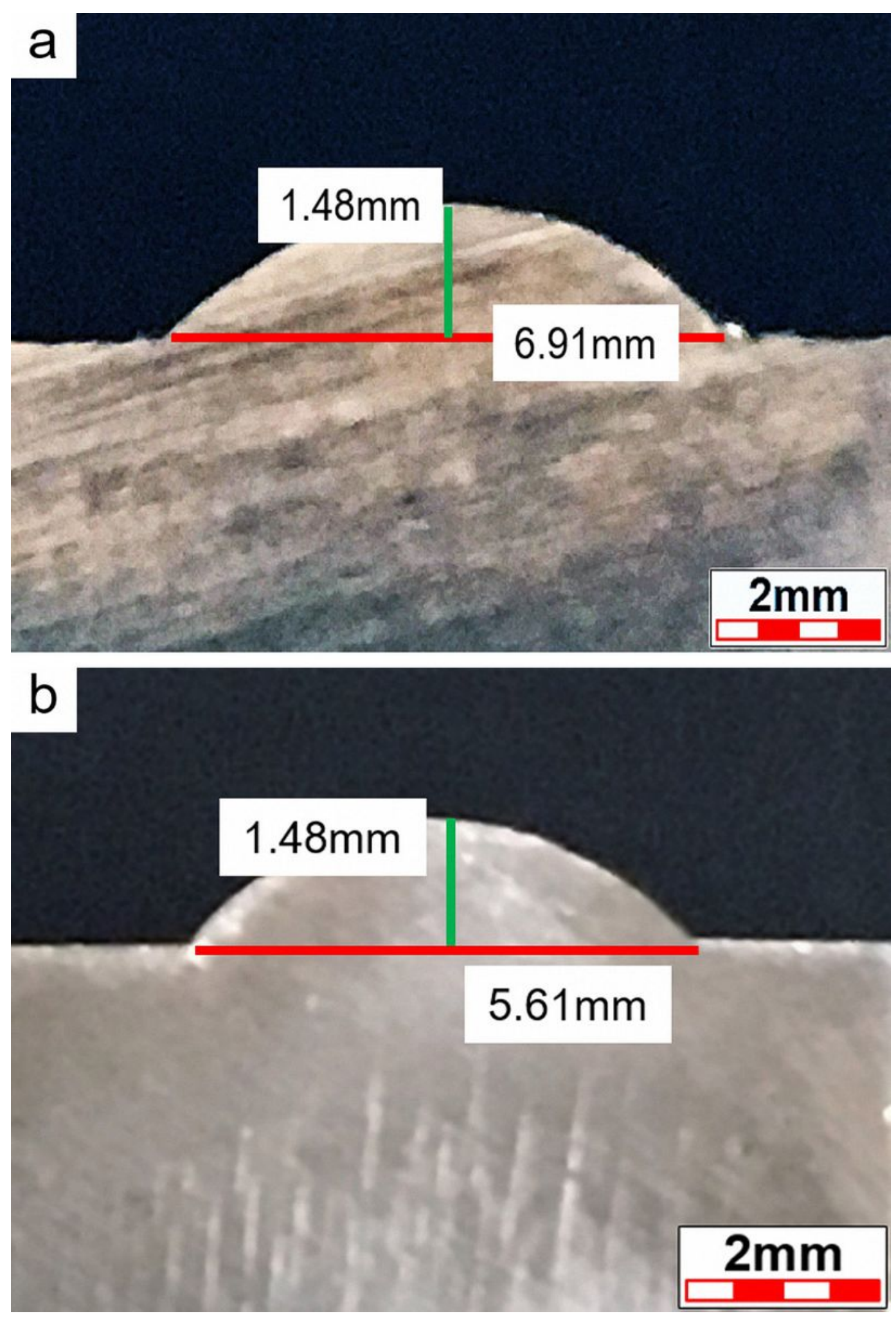

Figure 9

EPMA compositional analysis: (a) GATW weld bead Chinese script shaped carbide, and (b) GATW + EMS weld bead Chinese script shaped carbide. 

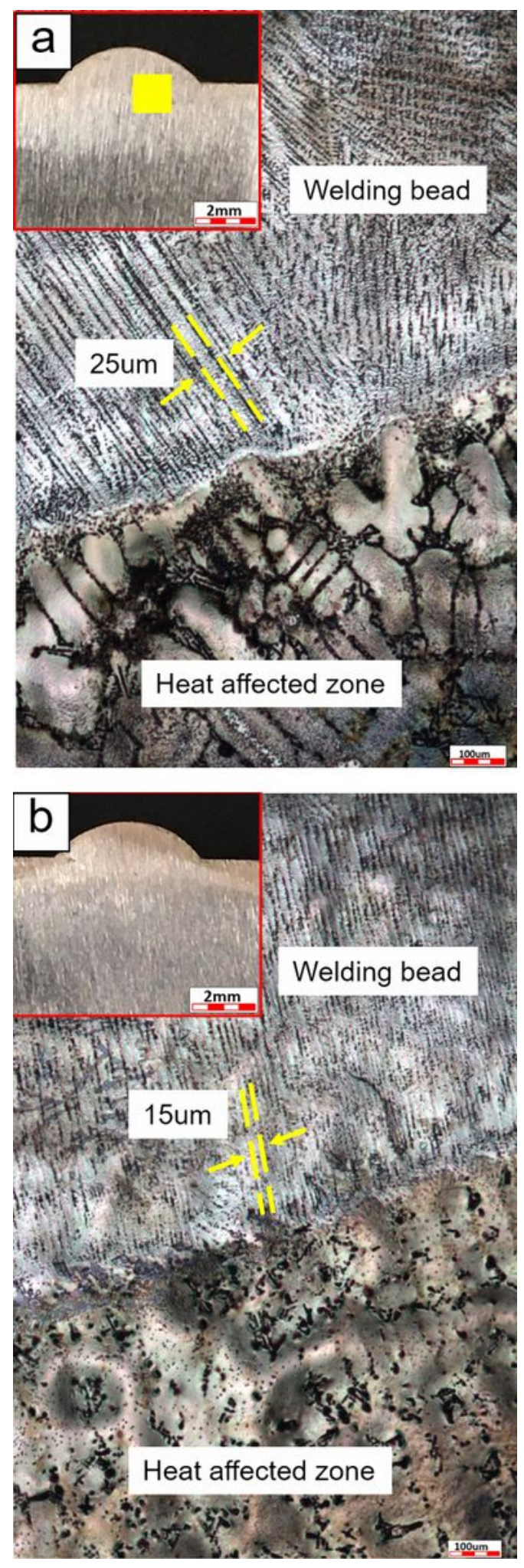

Figure 10

Microstructure of the weld bead and HAZ of GATW and GATW+ EMS on the specimens of solutionquenched MAR-M247 superalloy welded with using a Turbalay@625 solder. 


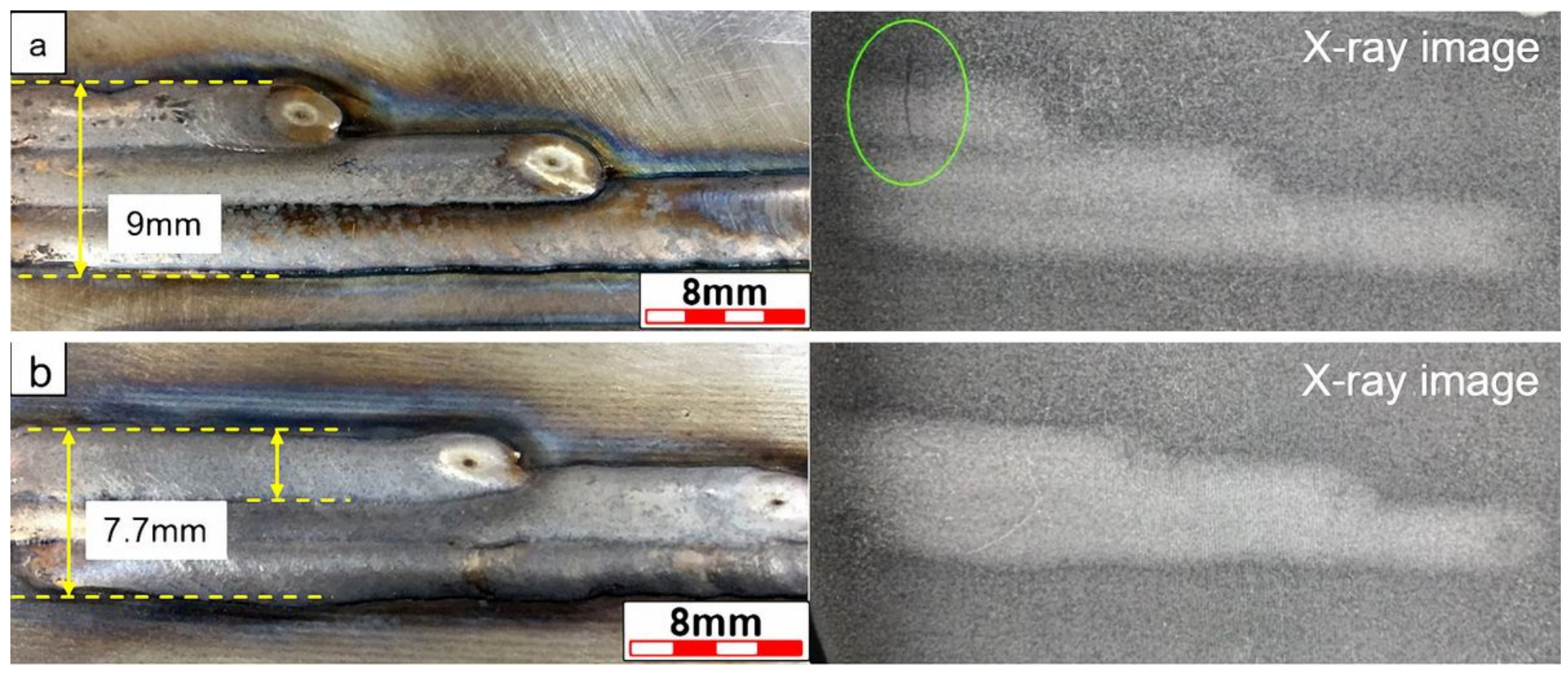

Figure 11

Three-pass overlay weld and X-ray analysis: (a) GATW; and (b) GATW + EMS.

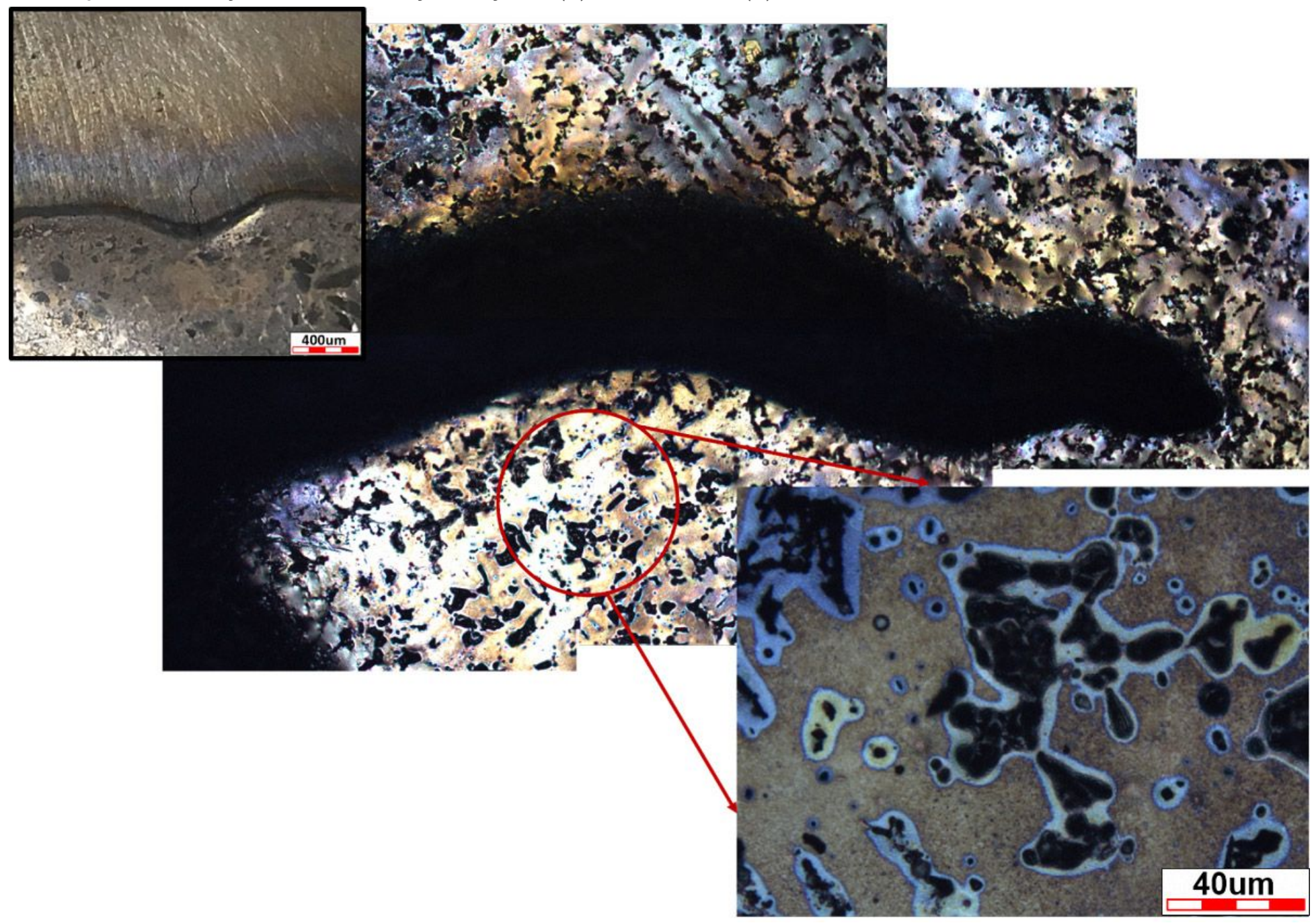


Figure 12

Welding crack morphology in the three-pass GATW overlay.
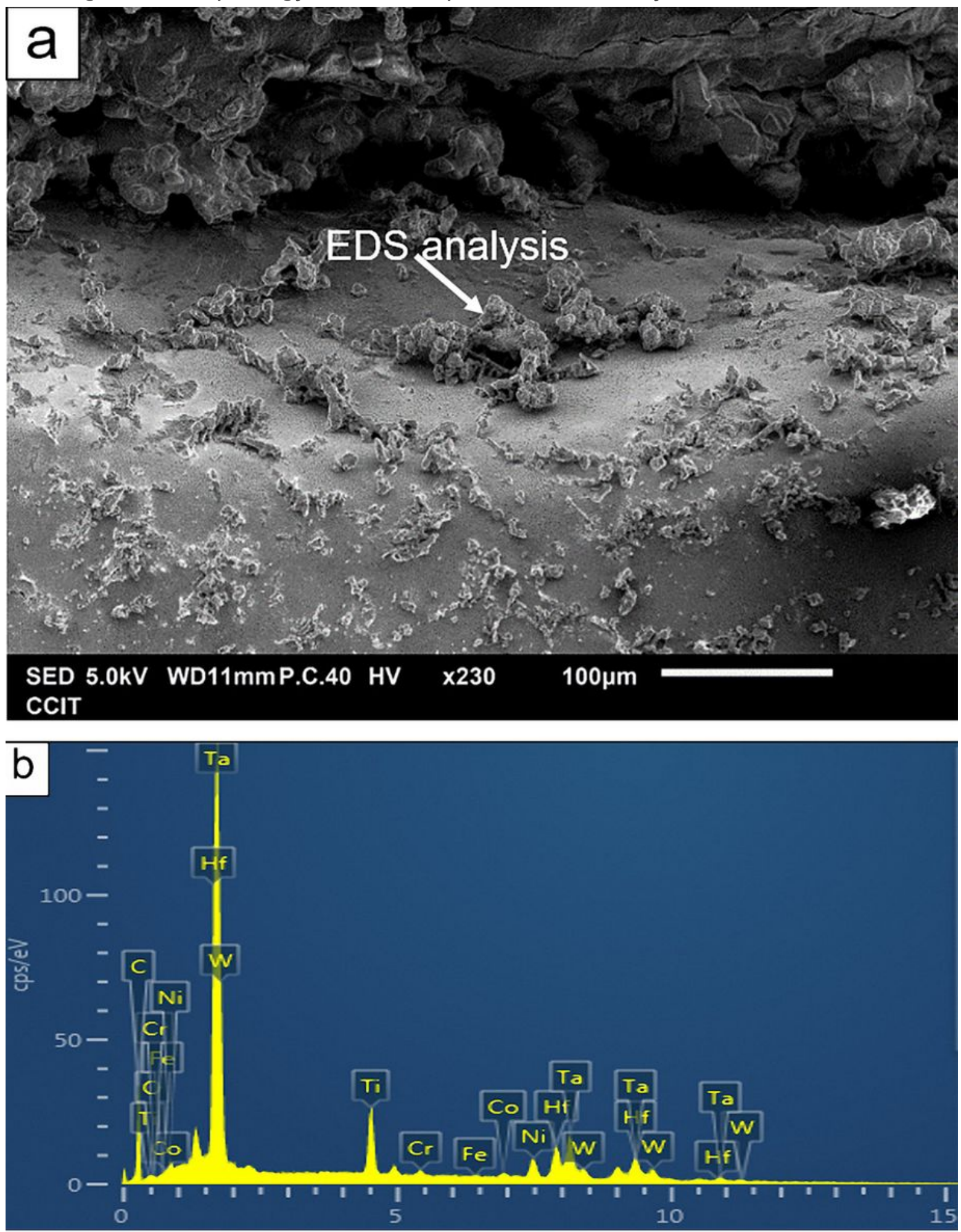

Figure 13

(a)SEM images and (b) energy dispersive spectrometer (EDS) analysis for the crack within three-pass GATW overlay. 


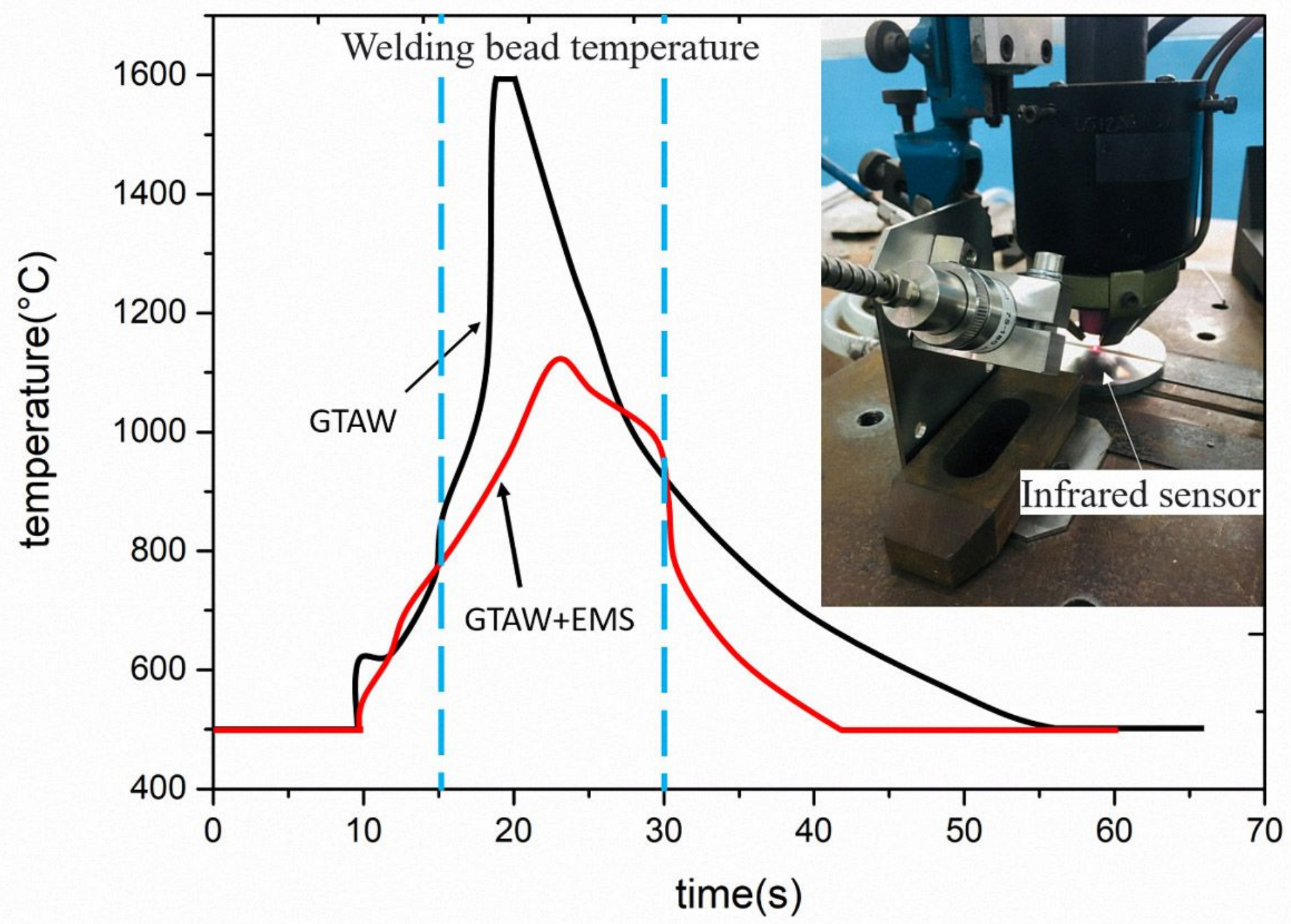

Figure 14

Instantaneous temperature of GATW and GATW + EMS arc passing through the central point of the HAZ of the welded workpiece measured using an infrared thermometer during the welding process. 


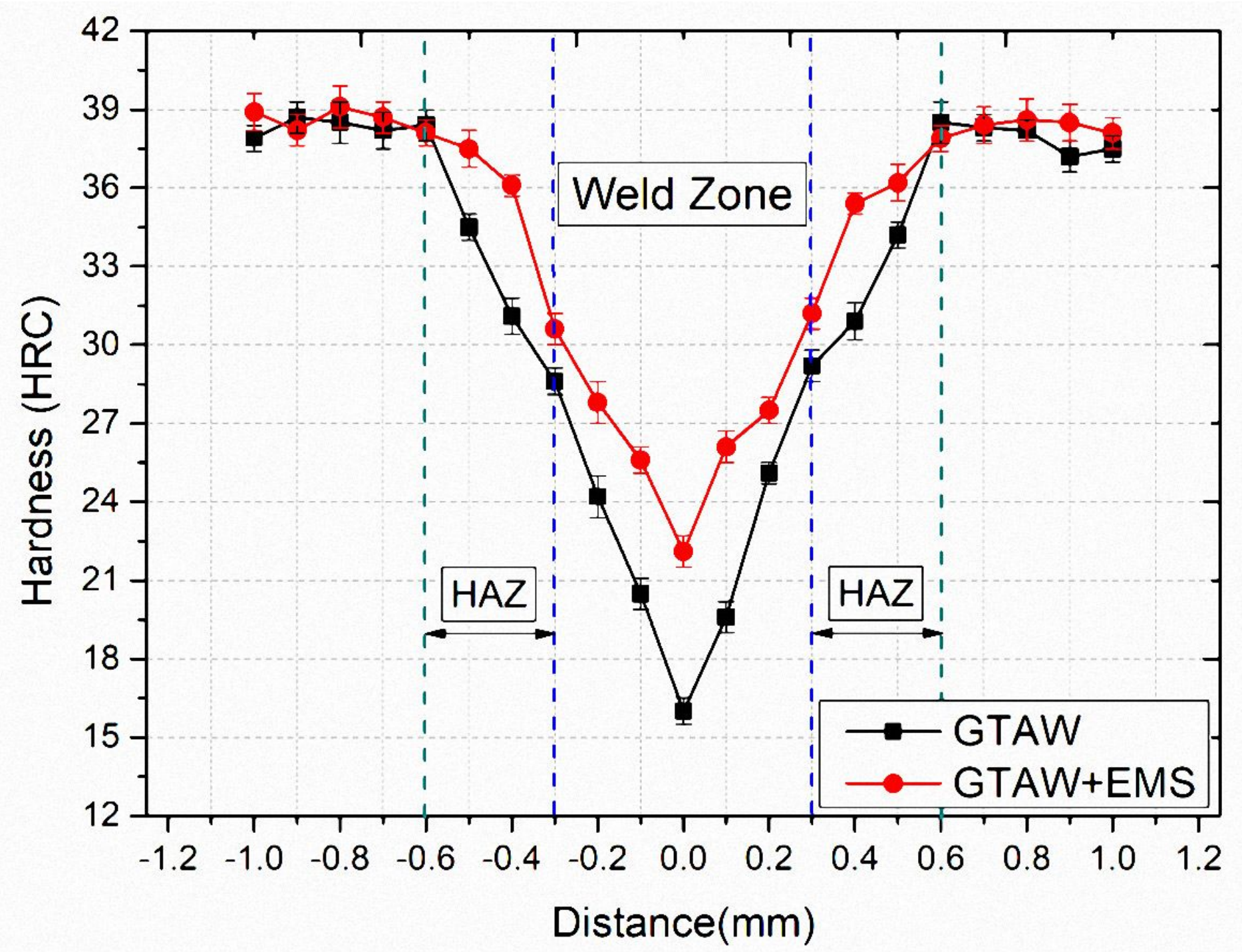

Figure 15

Hardness value of GATW and GATW + EMS welding along the center line of the welding cross section. 


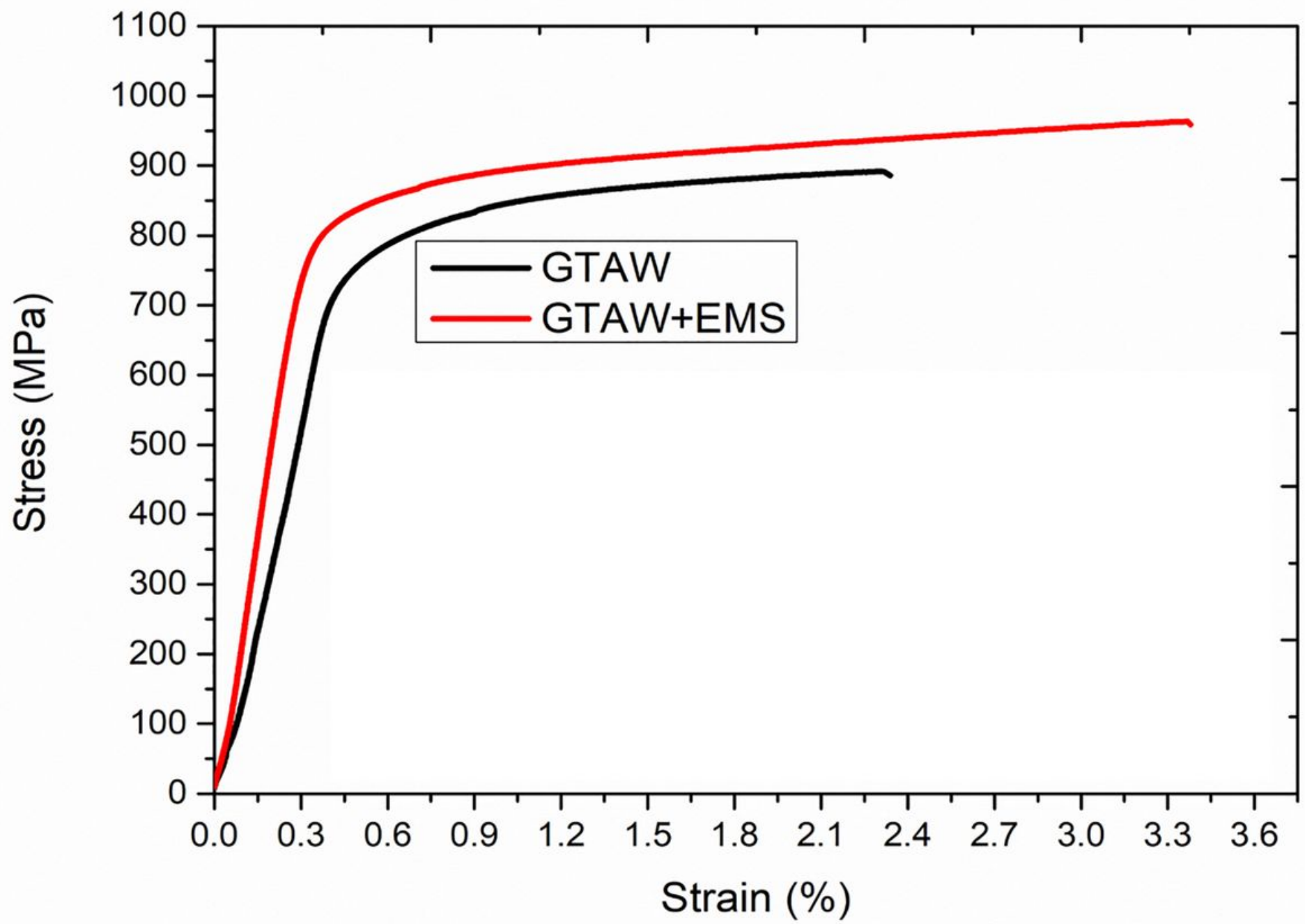

Figure 16

Tensile mechanical properties of GATW and GATW + EMS welded specimens of the MAR-M247 superalloy after heat treatment. 

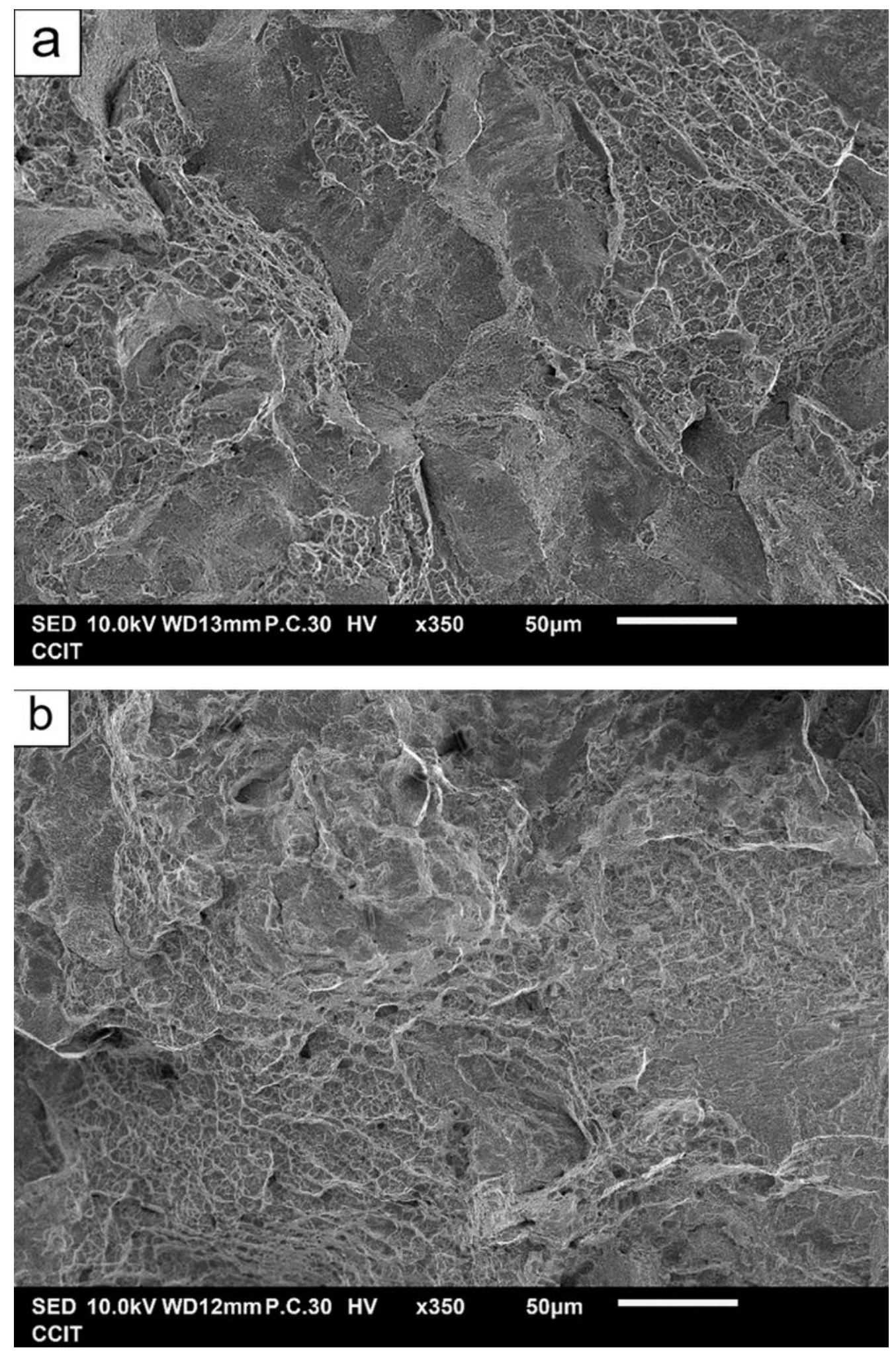

\section{Figure 17}

Tensile fracture surface of (a) GATW; and (b) GATW + EMS-welded specimens of the MAR-M247 superalloy. 